\title{
Broad Ligament Perivascular Epithelioid Cell Tumor (PEComa) of Uncertain Malignant Potential
}

\author{
Mary MATHEW, Bhavna NAYAL, Lakshmi RAO, Bhawna NAGEL \\ Department of Pathology, Kasturba Medical College, Manipal University, Manipal, KARNATAKA, INDIA
}

\begin{abstract}
PEComas are uncommon mesenchymal tumors often involving the pelvic organs. They have an unpredictable behavior. Accurate diagnosis and long-term follow-up is therefore essential in these patients. We report this case of PEComa of uncertain malignant potential in an unusual location with excellent prognosis.
\end{abstract}

Key Words: Perivascular epithelioid cell neoplasms, Broad ligament, HMB-45 protein

\section{INTRODUCTION}

Perivascular epithelioid cell neoplasms / tumors (PEComas) are tumors of mesenchymal origin characterized by perivascular epithelioid cells with distinctive histological and immunohistochemical features. According to the World Health Organization (WHO), the PEComa family consists of angiomyolipoma (AML), clear cell sugar tumor of the lung (CCST), lymphangioleiomyomatosis (LAM), clear cell myomelanocytic tumor (CCMMT) and unusual clear cell tumors of the pancreas, rectum, serosa, uterus, vulva, thigh and heart (1). These tumors can arise in various anatomic sites including bone, falciform ligament, mesentry, uterus, thigh and gastrointestinal tract (2). PEComas arising in the broad ligament are extremely rare. Only seven cases have been reported in the literature (3-9). We report a case of PEComa involving the broad ligament in a young lady encasing the ureter resulting in obstructive uropathy.

\section{CASE REPORT}

A 33-year-old female presented with primary infertility and complaints of dysmenorrhea, dyschezia and dysuria of 6 years duration. No other systemic abnormalities were detected. Abdominopelvic ultrasound demonstrated a well-defined, hyperechoic, heterogeneous mass in the left adnexa with multiple peripheral foci of calcification and internal vascularity along with left sided hydroureteronephrosis. CT abdomen and pelvis showed a well-defined enhancing soft tissue lesion measuring $3.5 \times 3.1 \times 5 \mathrm{~cm}$ with few specks of calcification and central non enhancing hypodense areas in the left adnexa. Left sided hydroureteronephrosis secondary to compression

(Turk Patoloji Derg 2016, 32:44-46)

Received : 15.10.2012 Accepted : 05.02.2013 or infiltration of the distal ureter at the level of trigone was also noted. A clinical diagnosis of broad ligament fibroid was entertained. The mass was excised and ureteric reimplantation was performed. Intraoperatively, the uterus and bilateral ovaries were normal. A highly vascular mass measuring $5 \times 4 \mathrm{~cm}$ on the left side of the uterus was noted with the left ureter traversing through the mass and resulting in marked dilation. The excised mass was sent for histopathological examination. Gross examination showed a single, grey brown mass weighing $18 \mathrm{gm}$ and measuring $5 \times 4 \times 2 \mathrm{~cm}$. The cut section of the mass showed a well circumscribed tumor with variegated appearance and grey white friable areas (Figure 1). Microscopy revealed nests of epithelioid tumor cells with moderate clear cytoplasm, vesicular nuclei and prominent nucleoli arranged around hyalinised blood vessels. In addition, occasional atypical cells with pleomorphism were noted (Figure 2). The mitotic count was $<1 / 50$ high power field (hpf). There was no evidence of necrosis or vascular invasion. The tumor cells stained positive for HMB 45 (Figure 3) and smooth muscle actin (Figure 4), and negative for S100 and CK. A final diagnosis of perivascular epithelioid cell tumor with uncertain malignant potential was rendered. Biannual follow up for two years did not show any recurrence or evidence of metastasis.

\section{DISCUSSION}

Perivascular epithelioid cell tumors are a family of tumors composed of epithelioid cells with abundant clear to eosinophilic cytoplasm and immunoreactivity to HMB45 (3). Tumors classified under this family are renal and extrarenal AML, LAM, CCST along with extrapulmonary

Correspondence: Bhavna NAYAL

Department of Pathology, Kasturba Medical College, Manipal University, Manipal, KARNATAKA, INDIA

E-mail: bhavnayal@yahoo.com Phone: +91 8202575060 


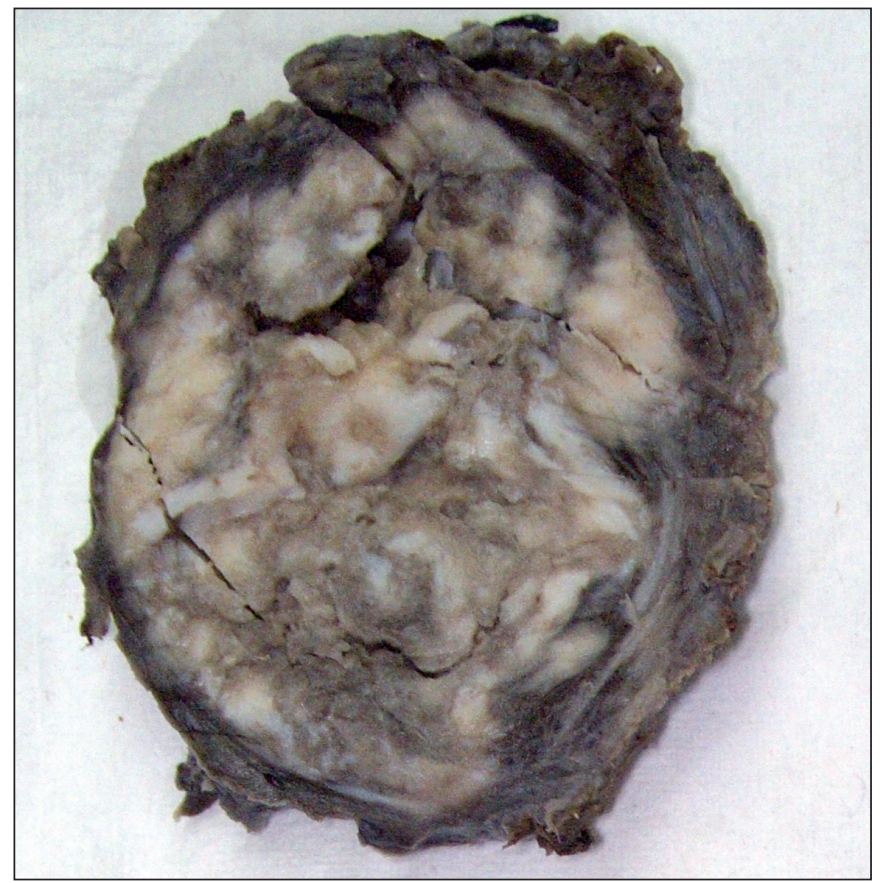

Figure 1: Cut section of a well circumscribed tumor with variegated appearance.

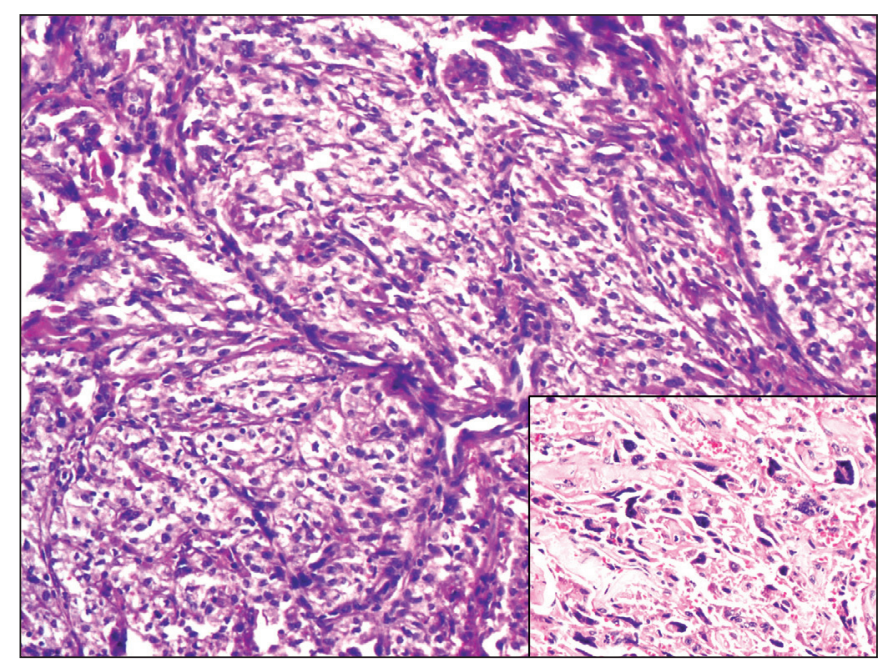

Figure 2: Nests of epithelioid cells with intervening blood vessels. Inset shows focal areas with atypia and pleomorphism (H\&E, $\mathrm{x} 400)$.

spindled and epithelioid tumors including CCMMT, primary extrapulmonary sugar tumor (PEST) and abdominopelvic sarcoma of perivascular epithelioid cells. This classification is based on histological features and anatomic site (2). The gynecologic tract is the most common site of involvement, with majority of cases reported in the uterus. PEComa arising from the broad ligament is extremely rare. These tumors show a female preponderance and affect middle aged individuals (4-7).
Tuberous sclerosis has been associated with AML and LAM. However, only $9 \%$ of the soft tissue and gynecologic PEComas are associated with tuberous sclerosis $(2,4)$. The present case did not show any stigmata of tuberous sclerosis.

Morphologically, PEComas are characterized by epithelioid and spindle cells arranged around vascular channels. Admixture of both type of cells are common. Electron microscopy reveals pre-melanosomes in the tumor cells $(2,3)$. Immunohistochemistry aids in confirming the diagnosis. These cells are positive for melanocytic markers, namely HMB45, Melan A and MiTF and smooth muscle actin (SMA). Few cases may be positive for S-100 $(2,4)$. This case demonstrated the characteristic histological features along with HMB45 and SMA positivity confirming the diagnosis of PEComa.

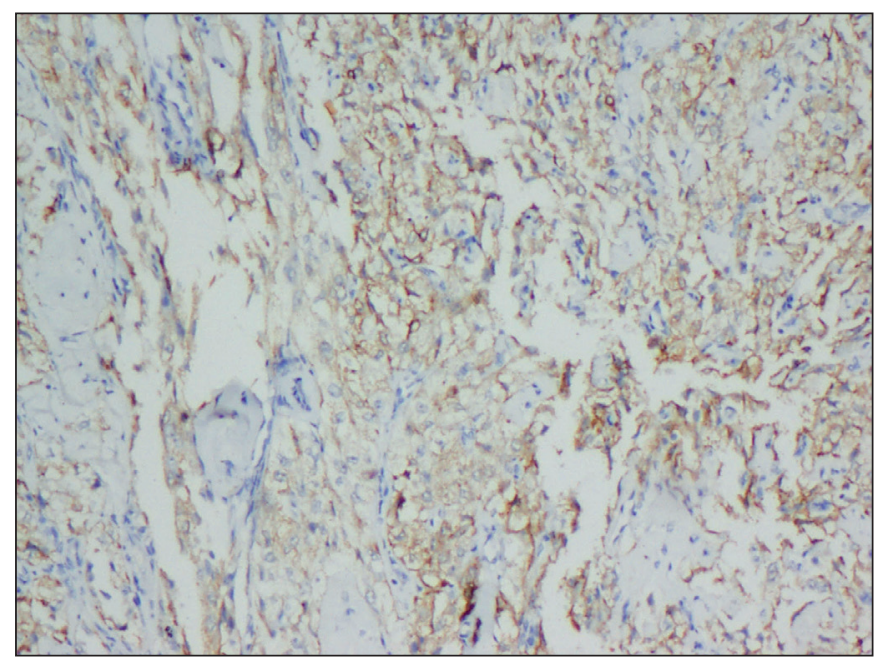

Figure 3: Epithelioid cells demonstrating HMB 45 immunoreactivity (HMB45; x400).

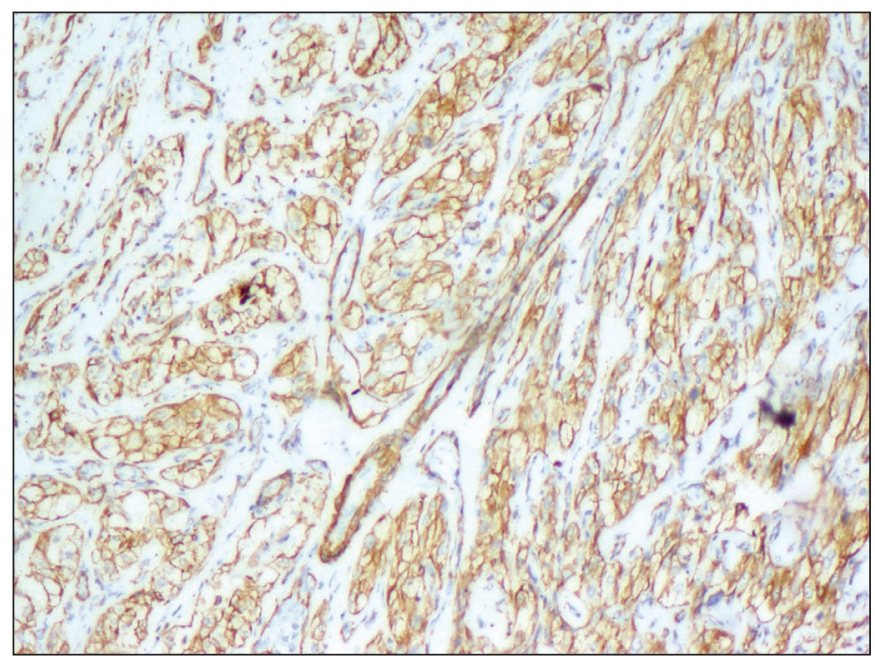

Figure 4: Epithelioid cells demonstrating smooth muscle actin immunoreactivity (SMA; $\mathrm{x} 400)$ 
PEComas are classified into benign, of uncertain malignant potential and malignant tumors for prognostication. This is based on tumor size $(>5 \mathrm{~cm})$, infiltration, high nuclear grade, increased cellularity, high mitotic activity ( $>1$ mitotic figure/50 high power fields) and tumor necrosis. Malignant PEComas have two or more of these features. Tumors of uncertain malignant potential include those with nuclear pleomorphism/multinucleate giant cells or $>5 \mathrm{~cm}$ in size (4). The present case was classified as PEComa of uncertain malignant potential, emphasizing the need for a long term follow up. Our patient is on periodic follow-up for the last two years and remains asymptomatic.

With regard to molecular mechanism involved in PEComas, there is activation of mammalian target of rapamycin (mTOR), a kinase causing suppression of T cell proliferation and inhibition of cell cycle progression. These processes are initiated by antigens and cytokines. The tumor suppressor genes TSC1 and TSC2, regulate the activity of mTOR. Hence, deletion of these genes causes up regulation of $\operatorname{mTOR}(3,10)$.

The differential diagnosis of PEComa includes clear cell sarcoma, clear cell carcinoma, conventional melanoma, epithelioid smooth muscle neoplasm, endometrial stromal sarcoma, gastrointestinal stromal tumor and paraganglioma. The morphological features, immunohistochemistry and electron microscopy aid in accurate diagnosis (3-5).

PEComas are treated by excision of the mass, salpingooophorectomy or total abdominal hysterectomy with bilateral salpingo-oopherectomy $(3,6,8)$. Sirolimus, an immunosuppressive agent, inhibits the activity of mTOR and is useful in the treatment of PEComa (10). Our patient underwent mass excision. Since the mass was encircling the ureter, ureteric resection and reimplantation was necessary. No radical surgery was performed as her age and desire to conceive were major concerns.

\section{REFERENCES}

1. Folpe AL. Neoplasms with perivascular epithelioid cell differentiation (PEComas). In Fletcher CDM, Unni KK, Epstein J, Mertens F, editors. Pathology and genetics of tumors of soft tissue and bone. WHO Classification of Tumors. Lyon: IRAC Press; 2002. 221-2.

2. Enzinger FM, Weiss SW, Goldbum JR. Soft tissue tumors of intermediate malignancy of uncertain type. In: Enzinger and Weiss's Soft Tissue Tumors. 5th ed. Philadelphia: Mosby Elsevier; 2008. 1093-160.

3. Ross C, Sharma S, Louca O, Scurr M, Hayes A, Judson I. A patient presenting with a perivascular epithelioid cell tumor in the broad ligament: A case report. J Med Case Rep. 2011;5:383.

4. Folpe AL, Mentzel T, Lehr HA, Fisher C, Balzer BL,Weiss SW. Perivascular epithelioid cell neoplasms of soft tissue and gynecologic origin: A clinicopathologic study of 26 cases and review of the literature. Am J Surg Pathol. 2005; 29:1558-75.

5. Fukunaga M. Perivascular epithelioid cell tumor of the uterus: Report of four cases. Int J Gynecol Pathol. 2005;24:341-6.

6. Kim HJ, Lim SJ, Choi H, Park K. Malignant clear-cell myomelanocytic tumor of broad ligament-a case report. Virchows Arch. 2006;448:867-70.

7. Fink D, Marsden DE, Edwards L, Camaris C, Hacker NF. Malignant perivascular epithelioid cell tumor (PEComa) arising in the broad ligament. Int J Gynecol Cancer. 2004;14:1036-9.

8. Rys J, Karolewski K, Pudelek J, Kruczak A, Wasilewska A, Vogelgesang M, Kojs Z. Perivascular epithelioid tumour (PEComa) of the falciform/broad ligament. Pol J Pathol. 2008;59:211-5.

9. Bonis RT, Dominguez TP, Calatayud FR, Jimenez EC, Piris MA, Lopez-Lucendo NJ. Pelvic PEComa of the broad ligament with lymph node metastasis: A case report and bibliographic review. Arch Esp Urol. 2008;61:744-8.

10. Wagner AJ, Malinowska-Kolodzeij I, Morgan JA, Qin W, Fletcher CD, Vena N, Ligon AH, Antonescu CR, Ramaiya NH, Demetri GD, Kwiatkowski DJ, Maki RG. Clinical activity of mTOR inhibition with sirolimus in malignant perivascular epithelioid cell tumors: Targeting the pathogenic activation of mTORC1 in tumors. J Clin Oncol. 2010;28:835-40. 